\title{
Food Insecurity and Coping Strategies amongst Students at University of Witwatersrand
}

\author{
Michael Rudolph, Florian Kroll, Evans Muchesa, Anri Manderson, Moira Berry, Nicolette Richard* \\ Wits Siyakhana Initiative, Republic of South Africa, 2001 \\ *Corresponding author: mikerud@telkomsa.net
}

\begin{abstract}
This study described food security status and explored coping mechanisms of students at times of food insecurity at the University of the Witwatersrand. The sample consisted of 387 undergraduate students from all faculties and a subsample of 30 students who received financial aid. The 30 subsample students were also assessed regarding their coping strategies. Action research approaches included key indicators such as the Household Food Insecurity Access Scale (HFIAS), and the Dietary Diversity Score (DDS). The HFIAS score showed that $1 \%$ of students was severely food insecure and 6\% were identified as moderately food insecure. The DDS score amongst the sample was seven out of a possible 12 points. African male students originating from townships who were on financial aid and did not eat in university dining halls were the most vulnerable group to food insecurity. Almost all (97\%) participants believed hunger could impact negatively on academic performance and 52\% reported having personally experienced the impact of hunger on academic performance. Food security coping strategies used by students were avoiding expensive fast-food places; food pooling, shared meal preparation schedules; eating fewer meals and going home to get food. Wits should develop effective strategies to address pockets of hunger and food insecurity.
\end{abstract}

Keywords: Action research, food security, academic performance, students, coping strategies, social status and university

Cite This Article: Michael Rudolph, Florian Kroll, Evans Muchesa, Anri Manderson, Moira Berry, and Nicolette Richard, "Food Insecurity and Coping Strategies amongst Students at University of Witwatersrand." Journal of Food Security, vol. 6, no. 1 (2018): 20-25. doi: 10.12691/jfs-6-1-2.

\section{Introduction}

Food insecurity at Higher Education Institutions (HEI) in South Africa has been reported as very high. There is a causal relationship between food insecurity and student academic performance with up to a $50 \%$ - $60 \%$ student dropout rate [1]. The FOA [2] states that food insecurity is the state of being without reliable access to a sufficient quantity of affordable, nutritious food. Food insecurity at HEIs is not a new phenomenon. However, it is not openly discussed especially at an institutional leadership level [3]. A key question is how the universities in collaboration with other relevant stakeholders can engage in finding common workable interventions on food insecurity at HEIs. Food insecurity is a global problem and is therefore the moral duty of politicians, senior management of HEIs and corporates, academics, students and all those in possession of resources to alleviate and address food insecurity with strong emphasis on sustainability particular amongst vulnerable populations including the important student population [4].

\section{Literature Review}

Institutions of Higher Education and Food Insecurity

"University food security studies use different methods of measuring and analysing food insecurity. Nevertheless, estimates among university students ranged from $11 \%$ to $38.3 \%$ in South Africa [5] $12.7 \%$ to $46.5 \%$ in Australia [6], $21 \%$ in Hawai'i [7] and $39.2 \%$ in New York, USA (Freudenberg et al. 2011). Effective research methods used by these studies included considering the relationship between food insecurity and item expenditures and the use of trained students to do the interviews for gathering data [1].

In South Africa less than $1 \%$ of the population holds a university degree. Tshiunza [8] citing a Department of Higher Education report showed that only $15 \%$ of students in South Africa graduate. The author [8] showed that the prevalence of food insecurity according to a one-item measure was $65 \%$. Using a 10 -item measure, $60 \%$ of the students experienced food insecurity "with hunger", and $26 \%$ food insecurity "without hunger". The highest prevalence of food insecurity was amongst black and coloured undergraduate, first-generation and male students, as well as in students who were unmarried, unemployed and those who depended on loans or bursaries. Using the regression model, the strongest significant predictors of food insecurity were race, gender, being a first-generation student, not having enough food money, having borrowed food money from parents, having asked for food and having sold belongings to obtain food.

The hungry UFS students came mainly from poor, rural backgrounds. They struggled to support themselves while studying. However, students were reluctant to discuss the problem openly because they were embarrassed and feared being stigmatised. Other studies done at University 
of Kwazulu Natal and North West University indicated that food insecurity amongst students was s $31.9 \%$ in the Free State, 34.4 in Kwa-Zulu Natal and almost 30\% in North West [9].

Food security exists when "all people, at all times, have physical and economic access to sufficient, safe and nutritious food to meet their dietary needs and food preferences for an active and healthy life" [2]. This widely accepted World Food Summit definition points out the four dimensions to food security: availability (production, distribution, exchange), access (entitlements to food, affordability, preferences), utilisation (social and nutritional values, food safety) and stability (access to adequate food at all times) [2]

Globally, concerns have been raised that food systems are changing rapidly to support a growing population of which more than half reside in cities since 2007 [16] There is need for more research so that there is an understanding of the intricate dynamics of urban food systems, which differ from rural food systems, and which in turn inform future strategies on sustainable urban food structures [7].

Crush et al [7] argued that food insecurity estimations depend on the measurement tools used and to which populations these tools are applied. These authors stated that there are no certain national South African food insecurity statistics. They refer to the difference between the National Food Consumption Survey of 2005 and the General Household Survey of 2007 that reported 10.6\% of adults to be food insecure. Although the latter survey had official status, it only used one question to measure food insecurity, whilst the former study was unofficial and conducted on a smaller scale, yet was a more in-depth study??In a recent study carried out in the wider Johannesburg Metropole, approximately one in five respondent households appeared severely food insecure, and one in three moderately insecure. This suggests that within the greater Johannesburg metropolitan area, approximately 6 million may be food insecure which incorporates many students. The Household Food Insecurity Access Prevalence score indicated that $34 \%$ are severely food access insecure, while $19 \%$ and $10 \%$ were moderately and mildly insecure respectively [10].

\section{Methodology}

This study investigated the status of food security of University of Witwatersrand (Wits) undergraduates and their coping mechanisms during times of food insecurity. A random sampling method was utilized to source research participates. An interview was conducted with the support and involvement of the then in-office President of the Students Representative Council. The investigations were divided into three phases: 1) the development and administration of questionnaires using an action research approach; 2) data-capturing and analysis of the questionnaires; and 3) focus group discussions that complimented the quantitative outputs of the questionnaires with contextual narratives. A questionnaire was designed and applied to 400 Wits undergraduates, which constituted a representative sample of the undergraduate population. The food security questionnaires were complimented by three focus group discussions that were themed as follows: Hunger on Wits campuses. The theme of the third focus group discussion was: 'Possible interventions', to discuss coping strategies for students. A subsample of 30 students who received financial aid and who were living at the Esselen residence was randomly selected, (10\% representative sample of the 300 students). These students were assessed about their food security status and explored their food security coping strategies.

Food security questionnaire

The questionnaire consisted of two main sections; measuring the food security of undergraduates and collecting data regarding their socio-economic status. Two internationally standardised and validated food security measurements were used for the first part of the questionnaire: the Household Food Insecurity Access Scale (HFIAS) and the Dietary Diversity Score (DDS). Although these indices were designed for household contexts, the questions in each measurement were adapted to apply to individuals within a university context. The DDS, designed by FANTA and used to supplement the HFIAS as a food access proxy measure, was included to measure the nutritional diversity of students' diets [11].

The second part of the food security questionnaire was divided into three parts designed to collect socio-economic data to correlate with students' food security scores: The data collected included information about accommodation and place of food consumption; perceptions of food security and eating habits, and finances.

Food Security Coping Strategies

This aspect of the study was qualitative in nature and sought to understand the coping strategies utilized by undergraduate students when faced with food insecurity. A random sampling method was utilized to source research participates. An interview was conducted with the in-office President of the Students Representative Council.

\section{Results}

Socio-demographic factors of the main sample group A total of 387 students participated in the food security questionnaire with slightly more than half of the sample being female and African students comprising $86 \%$ of the sample. All five university faculties where represented, with Humanities contributing the largest number of participants $(27 \%)$ and Health Sciences the least $(12 \%)$. Twenty three percent of students stayed in Wits catering residence and $30 \%$ lived at home. The majority of students shared accommodation (76\%), and $44 \%$ said they were responsible for buying their own food. Although only $54 \%$ indicated that they cooked together, $67 \%$ reported eating with roommates. Thirty two percent reported eating at Wits dining halls, confirming that day students sometimes also eat in dining halls (Table 1).

\subsection{Reasons Students Choose not to Eat}

The most common reasons given by students as to why they sometimes skipped meals included that it makes them feel sleepy (38\%), they have no time to eat (26\%) and they don't eat breakfast out of habit (19\%).(Table 2). 
Table 1. Socio-demographic factors of student sample

\begin{tabular}{|c|c|c|c|}
\hline Variable & Number $(\%)$ & Variable & Number (\%) \\
\hline \multicolumn{2}{|l|}{ Gender } & \multicolumn{2}{|l|}{ Faculty } \\
\hline Female & $199(53)$ & Health Sciences & $47(12)$ \\
\hline \multirow[t]{4}{*}{ Male } & $176(47)$ & Humanities & $102(27)$ \\
\hline & & Commerce & $79(21)$ \\
\hline & & Engineering & $69(18)$ \\
\hline & & Science & $80(21)$ \\
\hline \multicolumn{2}{|l|}{ Race } & \multicolumn{2}{|l|}{ Country } \\
\hline African & $321(86)$ & South Africa & $346(96)$ \\
\hline Coloured & $10(3)$ & Zimbabwe & $16(3)$ \\
\hline Indian & $20(5)$ & Other & $12(1)$ \\
\hline White & $18(5)$ & & \\
\hline Other & $5(2)$ & & \\
\hline \multicolumn{2}{|l|}{ Age } & \multicolumn{2}{|l|}{ Accommodation } \\
\hline \multirow[t]{5}{*}{ (mean, std) yrs } & $20.2(2.1)$ & Wits Catering & $86(23)$ \\
\hline & & Wits Self- & $10(3)$ \\
\hline & & catering & $118(32)$ \\
\hline & & Wits Private & $47(13)$ \\
\hline & & Private Home & $111(30)$ \\
\hline \multicolumn{2}{|c|}{ Shared Accommodation } & \multicolumn{2}{|l|}{ Who buys Food } \\
\hline \multirow[t]{2}{*}{ Yes } & $239(76)$ & Self & $101(44)$ \\
\hline & & Roommate & $128(56)$ \\
\hline \multicolumn{2}{|c|}{ Eat at Wits residence } & & \\
\hline Yes & $119(32)$ & & \\
\hline
\end{tabular}

Table 2. Reasons why students sometimes choose not to eat

\begin{tabular}{|l|l|}
\hline Factor & Number (\%) \\
\hline Makes one sleepy & $148(38)$ \\
\hline No time & $101(26)$ \\
\hline Don't eat breakfast & $73(19)$ \\
\hline Fasting & $62(16)$ \\
\hline Watching Weight & $57(15)$ \\
\hline Don't like the food & $50(13)$ \\
\hline No appetite & $49(13)$ \\
\hline Can't afford & $38(10)$ \\
\hline Faraway to get food & $26(7)$ \\
\hline Other reason & $21(5)$ \\
\hline Don't eat lunch & $18(5)$ \\
\hline Don't Eat Dinner & $5(1)$ \\
\hline
\end{tabular}

\subsection{Daily Number of Meals not Eaten}

Half of the students interviewed reported having missed at least one of the three main meals or more the day prior to the interview. The most likely meal to have been missed was breakfast (33\%). Breakfast has a significant effect on cognitive function during the day. If carbohydrate stores are not replenished during the early morning hours, the resulting low blood glucose levels can adversely affect one's ability to concentrate and perform mental tasks. Also, breakfast helps increase the ability to focus and reduces declines in attention and memory over the morning hours [3]. Forty two percent, 5\% and 4\% of participants respectively reported to have missed one, two and three meals respectively the previous day (Figure 1).

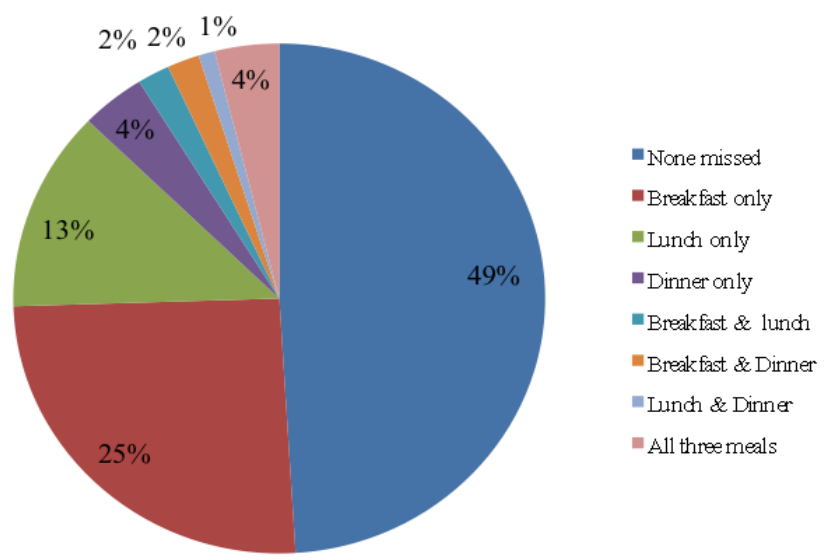

Figure 1. Percentage of meals students reported not eaten the previous day

\subsection{Hunger Scores}

The HFIAS showed that students sometimes had no food $(19 \%), 6 \%$ went to bed hungry $(6 \%)$ and $2 \%$ sometimes spent the whole day without food. When the last three food security questions were combined to create the Household Hunger $(\mathrm{HH})$ score, $1 \%$ of students were in the severe group and $6 \%$ were in the moderate group.

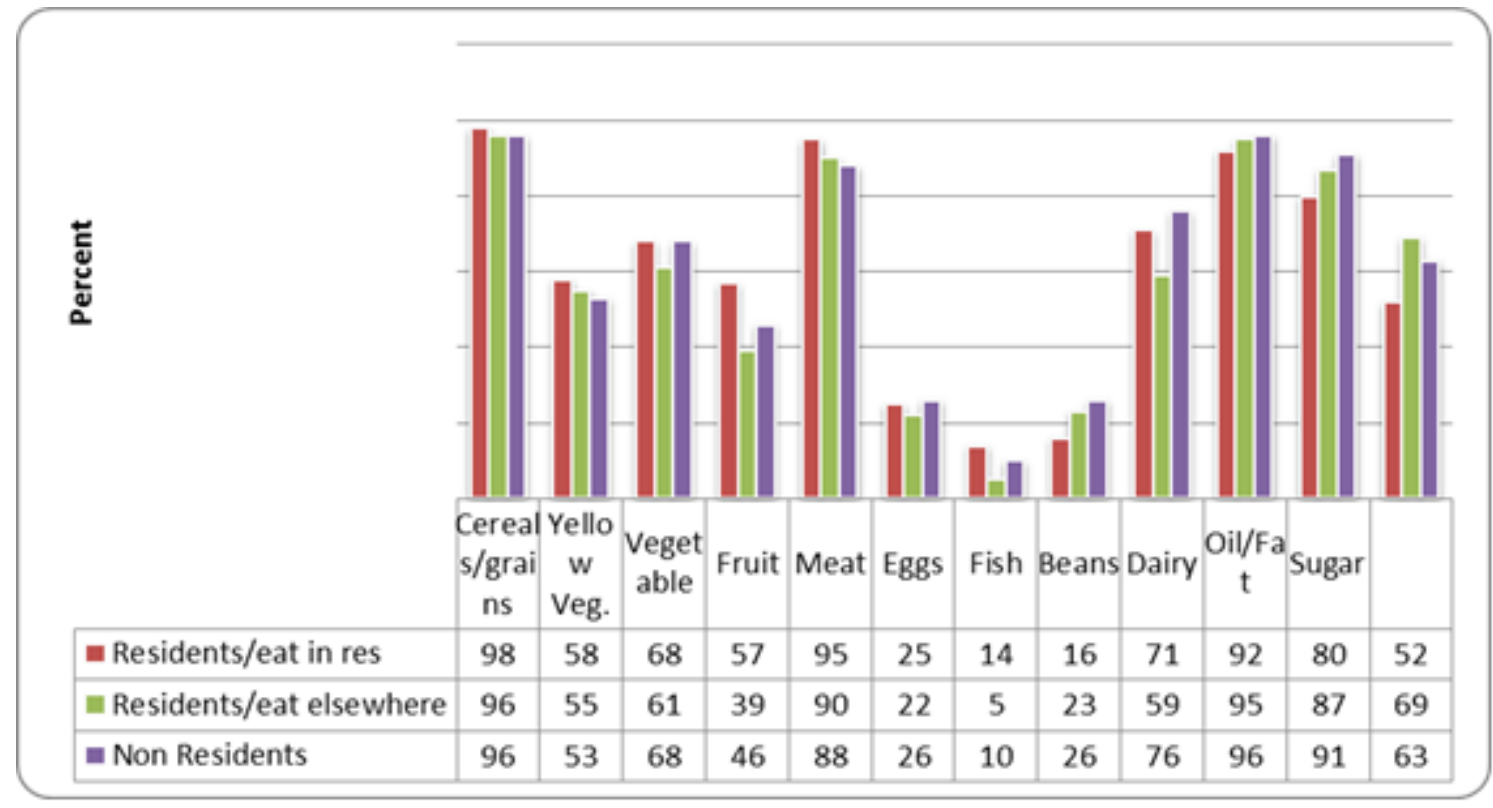

Figure 2. Percentage of food groups consumed by students in the previous day 


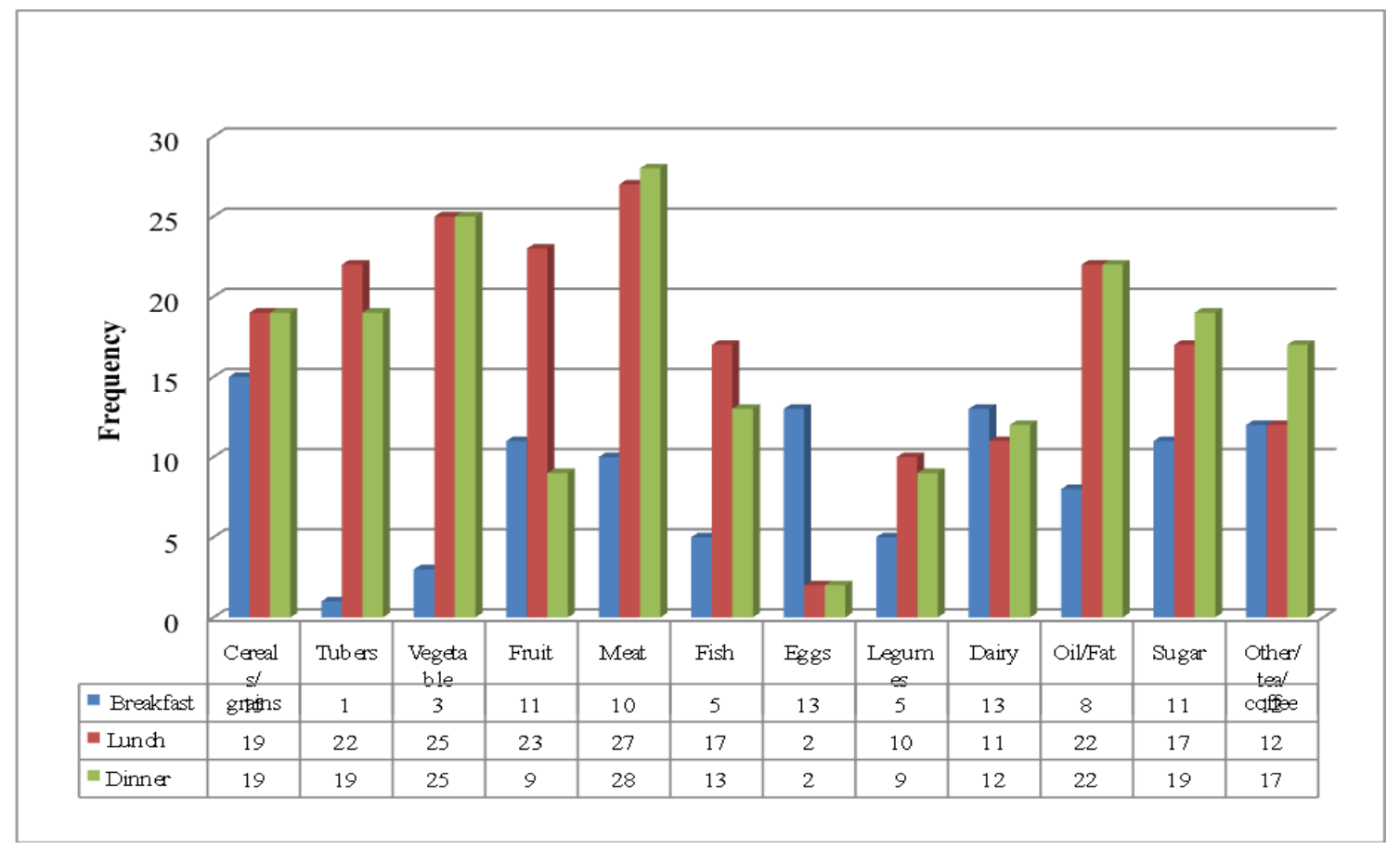

Figure 3. Students' perceived diversity of served meals in Wits dining halls

\subsection{Food Diversity Scores}

The median dietary diversity score for the meals consumed in the previous day was seven out of a possible total of 12 points. Students were more likely to have consumed starchy grain foods, meat, fat and sugar (Figure 2). The least likely food groups to be consumed were eggs, fish and legumes. The pattern of food groups consumed was similar regardless of whether students lived in Wits catering or non-catering residences ${ }^{1}$ or private accommodation (Figure 3).

\subsection{Food Diversity in Dining Hall Options}

When the food diversity shown in Figure 2 was compared to the student-reported available diversity in dining halls (Figure 3), it was clear that meat, oil and sugar comprise a large proportion of dining hall menus. The fact that oil/fat constituted more than $20 \%$ of the menu options could explain why students reported unhealthy cooking methods in dining halls in the first focus group discussion. However, tubers, vegetables and fruit also seemed to be available in sufficient quantities. Further investigation is necessary to understand why students made the choices they did.

\subsection{Knowing Whom to Approach for Help if Hungry}

Very few students knew whom to approach when unable to afford food. Twenty-two percent mentioned a person not in the options list, such as parents/relatives; $17 \%$ reported that there was no one to approach; twelve

\footnotetext{
${ }^{1}$ The Wits catering residences have dining halls offering their residents three meals a day. These dining halls are open to other students, but residence students are accommodated first. Self-catering residences do not offer a dining hall service and their students are responsible for providing their own food.
}

percent said the SRC, $11 \%$ the church, $8 \%$ did not know whom to approach. Only one food aid initiative was identified during this study - the Oppadami Meals programme but other programmes subsequent to this study have since been started which include; Gift of Givers daily meal, and Tigerbrands Food Parcel programme. Students could only qualify for this programme if identified and reported to the Dean of Students by the SRC, a Wits staff member or the CHWC.

\subsection{Cost of Meals}

Dinner was reported as the most expensive meal at a median cost of R25, while breakfast was the cheapest, at a median of R10 (Table 3). When this finding is compared to the average cost of meals provided by the three profiled clusters of food points on campus, it was clear that students spent less on meals than what was offered at these campus points. They were thus either not buying full meal options on campus or were buying food off-campus.

Table 3. Cost of meals

\begin{tabular}{|l|l|}
\hline Meal & Median cost Rands (min-max) \\
\hline Breakfast & $10(6-15)$ \\
Lunch & $20(15-30)$ \\
Dinner & $25(15-30)$ \\
\hline
\end{tabular}

\subsection{Monthly Amount Spent on Food}

The median amount of money on spent on food on a monthly basis ranged from R500 to R800. Students on Wits Financial Aid spent the least money on food at a median R500, while students on any other non-Wits bursary spent the most at a median of R800. Compared to the KwaZulu Natal study [5] which found that students spent an average R511 monthly (R128 weekly) four years prior to this study, thus Financial Aid students food expenditure was slightly less when considering inflation and increase of food prices. 


\subsection{Food Security Coping Strategies}

The following coping strategies were reported students. Food security coping strategies by the students $(\mathrm{N}=30)$

\begin{tabular}{|l|l|l|}
\hline Strategy & No. (\%) & Explanation \\
\hline Support Networks & $\mathbf{2 3}$ (77) & $\begin{array}{l}\text { Leveraging different networks of } \\
\text { relatives to cope with food } \\
\text { insecurity. }\end{array}$ \\
\hline Cheaper Food & $30(100)$ & $\begin{array}{l}\text { Getting cheaper foods; e.g.2 } \\
\text { minute noodles, downtown fruits } \\
\text { and vegetables, fizzy drinks and } \\
\text { buns amongst others. }\end{array}$ \\
\hline $\begin{array}{l}\text { Avoiding } \\
\text { expensive fast food }\end{array}$ & $30(100)$ & $\begin{array}{l}\text { Food on campus was expensive, } \\
\text { so they would get food } \\
\text { somewhere else. }\end{array}$ \\
\hline Meal Pooling & $20(67)$ & $\begin{array}{l}\text { Food pooling; friends would } \\
\text { decide based on a weekly } \\
\text { schedule who cooks for them, } \\
\text { after they have combined their } \\
\text { food together. }\end{array}$ \\
\hline $\begin{array}{l}\text { Going home to get } \\
\text { food }\end{array}$ & $13(43)$ & $\begin{array}{l}\text { Students save money and food } \\
\text { and opt to eating fewer meals; } \\
\text { skipping breakfast and having } \\
\text { only lunch and supper. }\end{array}$ \\
\hline Eating fewer meals & $28(93)$ & $\begin{array}{l}\text { This strategy was limited to } \\
\text { around Johannesburg and thus } \\
\text { could afford to travel. }\end{array}$ \\
\hline
\end{tabular}

\section{Discussion and Recommendations}

This study investigated the food security status of Wits undergraduates within the physical food environment and social and cultural setting of the university using a participatory research approach. This broader approach allowed a much more contextualised understanding of the food security situation.

Although the overall hunger score was relatively low (6\% moderately- and $1 \%$ severely vulnerable to food insecurity), there were clear pockets of hunger with African male undergraduates from townships on financial aid who were typically most vulnerable to food insecurity. Future food security studies should investigate other possible 'pockets of hunger' and how best to intervene.

The financial aid system at Wits, linked to the NSFAS, seems to be one of the key intervention points for addressing food security. The requirements and regulations of the scheme should be re-evaluated to ensure adequate financial support for various expenses, in particular food. The system should also have a built-in mechanism that teaches students basic financial management and budgeting for various essential expenditures.

Furthermore, the study identified that food and social status were closely related and that food choices could be 'status choices' motivated by a desire for an improved social status. The highly esteemed places included those in the profiled cluster that had direct contracts with Wits and were selling the most expensive, yet quality-perceived foods. Status foods included muffins, bottled water and filter coffee. Peeke and Van Alst [4] reported that eating refined carbohydrates like pasta can cause a rise in blood sugar, followed by a plunge in insulin levels, which can cause fatigue and weakness. Similarly white bread, pastries, muffins, and processed foods can cause drowsiness. Hence, food points offering these options deepened perceived social inequality among Wits undergraduates. There was an unequal distribution of food points, expensive food options and unhealthy food offered by food points had an impact on the food security status of students, both in terms of the quantity and quality of food consumed. Students' perceptions were that price was the most significant driver of food choices and hence consumed mostly starchy grains, meat, fat and sugar.

Only one food aid initiative was identified during this study - the Oppadami Meals programme but other programmes have since been started. Although undoubtedly supporting severely vulnerable students, the programme could consider other interventions which may be more effective and cost efficient. It should also be complimented by other interventions and approaches which address various factors which result in food insecurity. Effective communication of this and other programme should be clearly shared and discussed with students. Greater attention should be paid to new students entering the university environment in order to support vulnerable students and not leave them with an unfair disadvantage that would compromise their academic performance.

An important aspect of this study was that the questions of the HFIAS might not effectively measure food security in all situations, reinforcing arguments about appropriate metrics for measuring food insecurity [12]. The question about whether or not a student went to bed hungry is particularly ineffective in measuring food security in this study, as most students reported to eat dinner, even if it was the only meal of the day.

The impact of food insecurity on academic performance was not included in this study. However, based on student perceptions, food insecurity could have a negative impact on academic performance and could prevent students from completing their degrees, which would obviously be detrimental to these students, the Institution (Wits) and the larger South African society.

The following recommendations were identified to support food insecure students;

- Wits should have a clear policy with a dedicated budget for food security and nutrition;

- The Dean of Student Affairs and the SRC should further strengthen their existing awareness campaign and offer range of training programmes to inform students that hunger and poor nutrition impact on student outcomes ;

- Students should receive information about healthy foods, daily specials, feeding schemes, healthy food preparation via social media channels;

- Hungry students should be assisted anonymously, provide emotional and academic support, reliability of the food stipend and frequently monitored to avoid further stigmatization;

- Improve, enhance and extend food gardens on campus including roof food gardens.

- Establishing regular markets, box schemes selling local and organic food for staff and students. 


\section{References}

[1] Freudenberg. JS., Middleton. R.H., 2001. Minimum variance control over a Gaussian communication channel- IEEE Transactions on - ieeexplore.ieee.org.

[2] FAO. 2015. Regional Overview of Food Insecurity: Africa. African Food Security Prospects, Brighter than Ever.

[3] Scholey AB, Harper S, Kennedy DO.,2001. Cognitive demand and blood glucose. Physiol Behav 2001;73:585-592.

[4] Peeke, P and Van Alst M.,2013. The Hunger Fix: The Three-Stage Hunger and Recovery Plan for Overeating and Food Addiction

[5] Munro, N. 2009. 11\% of UKZN Students highly vulnerable to food insecurity. Student Counselling Quarterly 5(1).

[6] Masutha, M.M. 2011. Investigating the food security experience of financial aid students living in a self-catering residence of Esseen Street and the relationship between their food security status and their financial aid package. Bsc Honours Research Report, Wits University.

[7] Crush, J. and Frayne, B. 2010. The Invisible Crisis: Urban Food Security in Southern Africa. Urban Food Security Series 1. Cape Town: African Food Security Urban Network (AFSUN).

[8] Tshiunza, R. 2016. Food waste and security in higher learning institutions of South Africa: A study of the University of the Witwatersrand, Honours Research Report.

[9] Gwacela, M.,Chitja J.M., \&Kolanisi,U.,2013. Exploring Food Security and Socio-economic Factors Affecting Academic Performance: A Case Study of $1^{\text {st }}$ Year Students on Probation and at Risk of Academic Exclusion. Unpublished thesis. University of KwaZulu-Natal.

[10] Rudolph. M.R and Kroll. F. 2017. CITY OF JOHANNESBURG 2017- FOOD SECURITY SURVEY, Final Report. City of Johannesburg, Wits Commercial Enterprise.

[11] Swindale, A. and Bilinsky, P., 2005. Household Dietary Diversity Score (HDDS) for Measurement of Household Food Access: Indicator Guide. Washington, DC: Food and Nutrition Technical Assistance Project, Academy for Educational Development.

[12] Altman, M., Hart, T. and Jacobs, P. 2009. Food security in South Africa. Paper for the project: Ensuring affordable quality food for poor households: Considering the short- and long-term contribution of food security to the government's poverty and unemployment reduction strategies. Project jointly funded by ComMark Trust and the Human Sciences Research Council (HSRC) Parliamentary Grant Allocation, South Africa.

[13] Khoza, P.S. 2011. Food security coping strategies employed by undergraduate students at the University of the Witwatersrand on financial aid living in self-catering accommodation. Honours Research Report, Wits University.

[14] Munro, N., Simpson, H. and Quayle, M. 2007. Vulenrability to and effects of food insecurity on university students. University of KwaZulu Natal, South Africa. Email: munron@ukzn.ac.za.

[15] National Student Financial Aid Scheme. N.d. [Online]. Available: www.nsfas.org.za. (20 November 2011)

[16] Rudolph M and Kroll. F.2016. City of Johannesburg Food Resilience Programme Evaluation Final Report, Wits Commercial Enterprise, Wits Siyakhana Initiative, School of Geography, Archaeology and Environmental Studies (GAES), October 2016.

[17] Rudolph, M., Kroll, F., Ruysenaar, S., and Dlamini, T. 2011. Food security, poverty and health in three case study areas of Johannesburg. The University of the Witwatersrand: The Siyakhana Initiative for Ecological Health and Food Security. [Online]. Available: http://bit.ly/o6dgZt. (3 October 2011).

[18] Rudolph. M, Kroll.K, Ruysenaar.S \& Dlamini.S. 2012. "The State of Food Insecurity in Johannesburg." Urban Food Security Series No. 12. Queen's University and AFSUN: Kingston and Cape Town http://www.afsun.org/wpcontent/uploads/2013/09/AFSUN_12.pdf.

[19] Van den Berg.L.\& Raubenheimer .J.,2015. Food insecurity among students at the University of the Free State, South Africa. S Afr J Clin Nutr: ISSN (Print): 1607-0658, ISSN (Web): 2221-1268

[20] Willows, N.D. and Au, V. 2006. Nutritional quality and price of university food bank hampers. Canadian Journal of Dietetic Practice and Research 67(2):104-107.

[21] Wits Services Department (WSD). 2011. Wits 2001 SelfAssessment Report. Wits: Office of the Director: Services Management. Obtained from the Director, Theresa Main (e-mail: theresa.main@wits.ac.za). 